\title{
In vitro Release Kinetics Study of Diclofenac Sodium from Acrylic Polymer Coated Pellets
}

\author{
Golam Kibria and Reza-ul-J alil \\ Department of Pharmaceutical Technology, Faculty of Pharmacy, \\ University of Dhaka, Dhaka-1000, Bangladesh
}

\begin{abstract}
The aim of the present study is to investigate the effect of Ammonio Methacrylate Copolymer Type B (Eudragit RS $30 \mathrm{D}$ ) on the release kinetics study of diclofenac sodium form coated pellets. The effect of the incorporation of xanthan gum into the coating formulation was also the goal of this study. Eudragit RS $30 \mathrm{D}$ and xanthan gum was added into the formulation at 5:1 ratio. Different percent of this polymeric combination was loaded on to the drug-loaded pellets. It was found that the cumulative \% release of drug decreased with the increase of polymer load in all cases. From all formulations it was observed that the release of diclofenac sodium in $0.1 \mathrm{~N} \mathrm{HCl}$ media was very low (maximum 3.5\%) at first 2 hours. Better sustaining effect was found from Eudragit RS $30 \mathrm{D}$ and xanthan gum combinations. Drug was released linearly along with time throughout the whole dissolution process in phosphate buffer $\left(\mathrm{p}^{\mathrm{H}}\right.$ 6.8) and it was also revealed that, in all cases the release of diclofenac sodium followed mixed release kinetics but zero order release kinetics predominates.
\end{abstract}

Key words: Diclofenac sodium, pellets, sustained release, in vitro, kinetic analysis.

\section{INTRODUCTION}

In the recent years the popularity of sustained release pellets dosage form is rapidly increasing. The pellet type of sustained-release preparation is often referred to as bead-type preparation. In general the beads are prepared by coating drug powder onto perforated cores called nonpareil seeds. The drugcoated beads generally provide a rapid-release carrier for the drug depending on the coating solution used in coating the drug. Once the drug beads are prepared, they may be further coated with a protective coating to allow a sustained or prolonged release of the drug. ${ }^{1}$ Sustained release formulation of pharmaceutical pellet products has been widely investigated due to its tremendous demand in the pharmaceutical markets. This happens due to some

Correspondence to: Reza-ul-Jalil

Tel: 9120325; Fax: 880-2-8615583

E-mail: raju1559@yahoo.com

Dhaka Univ. J. Pharm. Sci. 6(1): 1-7, 2007 (June) advantages shown over conventional dosage forms. A major advantage of pellet dosage form is that the pellets are less sensitive to the effect of stomach emptying. Because there are numerous pellets within a capsule, some pellets will gradually reach the small intestine and deliver the drug; where as a single tablet may be delayed in the stomach for a long time due to erratic stomach emptying. ${ }^{1}$ The fluctuating drug concentrations in blood and tissues caused by conventional dosage forms lead to an insufficient influence on the mechanisms of disease and are related to the excessive use of drug. Various oral dosage forms able to control the rate and extent of drug delivery into systemic circulation have been prepared and studied. ${ }^{2-5}$

Aqueous film-coating dispersions generally consist of polymeric colloidal particles, a plasticizer, a pigment, and an anti-adherent agent. Most polymers employed for the film coating of pellets and tablets 
are brittle at room temperature and require the use of plasticizers to improve their handling and processing. ${ }^{6}$ Polymethacrylates are primarily used in oral capsule and tablet formulations as film coating agents. $^{7-9}$ Depending on the type of polymer used, films of different solubility characteristics can be produced. Eudragit RS $30 \mathrm{D}$ is the aqueous dispersion of copolymers of acrylic acid and methacrylic acid esters with a low content of quarternary ammonium groups. The dispersions contain $30 \%$ polymer. $^{10}$ The quarternary groups occur as salts and are responsible for the permeability of films made from these polymers. Films prepared from Eudragit RS $30 \mathrm{D}$ are less permeable to water and release the active substances through diffusion. Film coating prepared from both polymers give $\mathrm{pH}-$ independent release of active substance. Plasticizers are usually added to improve film properties. ${ }^{10}$ Xanthan gum is a polysaccharide gum and the aqueous solutions are stable over a wide $\mathrm{pH}$ range (pH 3-12) and temperatures between $10-60^{\circ} \mathrm{C}$. It is widely used to prepare sustained release matrix formulations and it acts by forming hydrogel through swelling as well as releases the drug through diffusion. ${ }^{11-14}$ As xanthan gum mainly used to get sustained effect from matrix formulations, this study is fabricated to observe its effect by using to some extent with Eudragit RS 30 D in the coating formulations of diclofenac sodium loaded pellets.

\section{MATERIALS AND METHODS}

Materials that are used throughout the experiment are diclofenac sodium (Square Pharmaceuticals co. Ltd. Bangladesh), Sucrose (Cerestar, Netherland), Lactose (The Lactose Co. of Newzealand Ltd. Newzealand), Maize Starch (Cerestar, Netherland), Purified Talc (Asian Mineral, Thailand), Titanium Dioxide (Warner Jenkinson, Italy), Triethyl Citrate (Morflex Inc.USA), Kollidon 30 (BASF, Germany), Eudragit RS 30 D (Rohm Pharma., Germany), Xanthan gum (Gumix Int., USA). All the other chemicals used were of analytical grade.

Preparation of diclofenac sodium sustained release pellets. Powder layering method was chosen to prepare the nonpareil seeds (NPS) first with sucrose, lactose, Kollidon 30 and purified water in the Centrifugal Fluidized Coater (Table 1). After completion of the process, NPS was dried at $60-70{ }^{\circ} \mathrm{C}$ for 6-7 hours in hot air oven and sieved through 25 \& 30 mesh respectively to get the desired size $(25 / 30)$ then loaded onto conventional coating pan and mixture of diclofenac sodium powder \& maize starch was loaded on NPS with simultaneous spraying of kollidon 30 \& water solution (Table 1). After completion of the process, drug loaded pellets was dried at $50-60{ }^{\circ} \mathrm{C}$ for $4-5$ hours in hot air oven and then sieved through $20 \& 25$ mesh to get the desired size.

Table 1. Core and coating formulation of diclofenac sodium sustained release pellets (weights are in g).

\begin{tabular}{lcccccc}
\hline \multirow{2}{*}{ Materials } & \multicolumn{5}{c}{ Formulations } \\
\cline { 2 - 6 } & $\begin{array}{c}5 \% \\
\text { polymer }\end{array}$ & $\begin{array}{c}10 \% \\
\text { polymer }\end{array}$ & $\begin{array}{c}15 \% \\
\text { polymer }\end{array}$ & $\begin{array}{c}20 \% \\
\text { polymer }\end{array}$ & $\begin{array}{c}25 \% \\
\text { polymer }\end{array}$ & $\begin{array}{c}30 \% \\
\text { polymer }\end{array}$ \\
\hline Diclofenac Sodium & 110 & 110 & 110 & 110 & 110 & 110 \\
Sucrose & 75 & 75 & 75 & 75 & 75 & 75 \\
Lactose & 90 & 90 & 90 & 90 & 90 & 90 \\
Maize Starch & 60 & 60 & 60 & 60 & 60 & 60 \\
Kollidon 30 & 25 & 25 & 25 & 25 & 25 & 25 \\
Eudragit RS 30 D* & 50 & 100 & 150 & 200 & 250 & 300 \\
Xanthan Gum & 3 & 6 & 9 & 12 & 15 & 18 \\
Purified Talc & 1.8 & 3.6 & 5.4 & 7.2 & 9 & 10.8 \\
Titanium Dioxide & 0.9 & 1.8 & 2.7 & 3.6 & 4.5 & 5.4 \\
Triethyl Citrate & 2.7 & 5.4 & 8.1 & 10.8 & 13.5 & 16.2 \\
Water up to & 350 & 600 & 900 & 1200 & 1500 & 1700 \\
\hline
\end{tabular}

$* 30 \%$ dispersion commercial grade is used. 
Then coating suspension was prepared by using Eudragit RS 30 D, xanthan gum, purified talc, titanium dioxide, triethyl citrate \& water (Table 1). Drug loaded pellets were loaded in the fluid bed coater \& coating suspension was sprayed. After completion of spraying, the coated pellets were dried at 50-60 ${ }^{0} \mathrm{C}$ for 5-6 hours in hot air oven and sieved through $18 \& 22$ mesh to get the desired size (18/22) of the diclofenac sodium sustained release pellets (Figure 1).
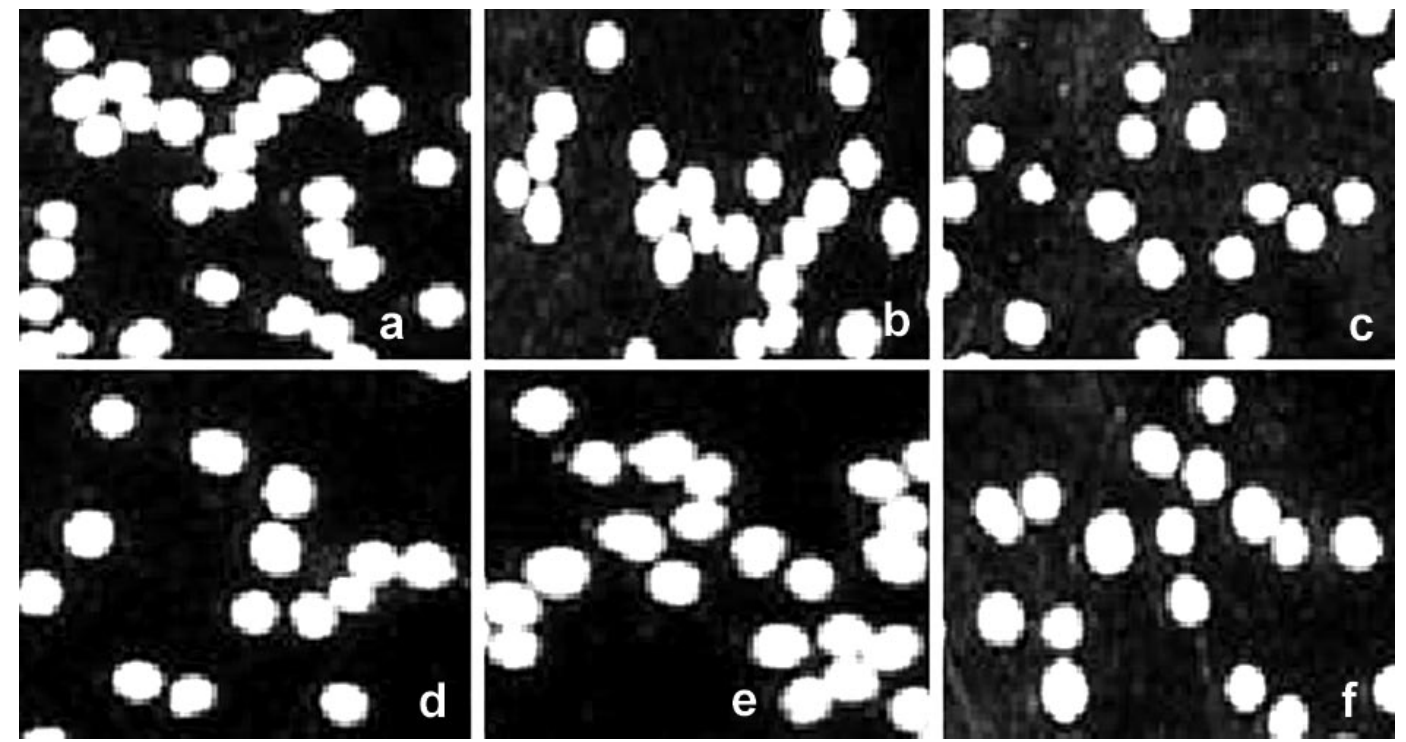

Figure 1. Diclofenac sodium sustained release pellets (dried \& sieved) coated with different percent of Eudragit RS 30 D and xanthan gum (5:1 ratio) load. [ (a): 5\% polymer load, (b): $10 \%$ polymer load, (c): $15 \%$ polymer load, (d): $20 \%$ polymer load, (e): $25 \%$ polymer load, (f): $30 \%$ polymer load]

In vitro dissolution study. The dissolution of diclofenac sodium sustained release pellets was studied by Erweka (Germany) dissolution tester USP (XXVIII) using USP apparatus 1 (Basket method). Diclofenac sodium sustained release pellets equivalent to $100 \mathrm{mg}$ of diclofenac sodium was poured in $900 \mathrm{ml}$ of $0.1 \mathrm{~N}$ hydrochloric acid medium at $37 \pm 0.5^{\circ} \mathrm{C}$ with a rotation of $100 \mathrm{rpm}$ for 2 hours. At the end of 2 hours the media was removed and drug content was determined spectrophotometrically at $276 \mathrm{~nm}$. Then $900 \mathrm{ml}$ of phosphate buffer $\left(\mathrm{Na}_{3} \mathrm{PO}_{4}\right) \mathrm{pH} 6.8$ was placed in each vessel and rotated at $100 \mathrm{rpm}$ at $37 \pm 0.5^{\circ} \mathrm{C}$ for 10 hours. Five $\mathrm{ml}$ samples were drawn every one hour and replaced by fresh medium to maintain the volume constant and drug content was determined spectrophotometrically at $276 \mathrm{~nm}$.

\section{RESULTS AND DISCUSSION}

Diclofenac sodium was loaded on nonpareil seeds by powder layering method and finally coated with aqueous dispersion of acrylic polymer (Eudragit RS 30 D) and xanthan gum combination using fluid bed coater. The drug release was studied by in vitro dissolution using USP basket method. Although xanthan gum was incorporated into the coating formulations for sustaining effect but it creates problem during preparation of coating solution and increases the solution volume more. This also creates difficulties in spraying and finally at the end of process the surface of the pellets found rough.

When diclofenac sodium loaded pellets were coated with 5 to $30 \%$ percent of the combination of Eudragit RS 30 D and xanthan gum polymers (5:1 ratio), then it was revealed that the polymers have significant release retarding effect in acid media and from all formulations maximum $2.5 \%$ drug was 
released at first 2 hours (Figure 2). In the buffer media, it was found that the drug release decreases gradually along with the increase in percent of polymer load from (5 to 30\%) and when the cumulative percent of drug release was plotted against time a linear relationship was observed in every formulation and was found to release the drug at a uniform rate in most cases (Figure 5a) which may be due to the presence of xanthan gum. ${ }^{15-17}$ It

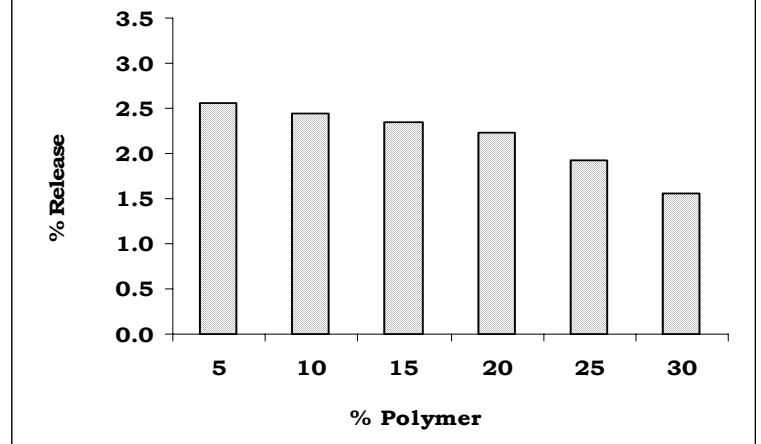

Figure 2. Release of diclofenac sodium from different percent of Eudragit RS 30 D \& xanthan gum (5:1) coated pellets at two hours in $0.1 \mathrm{~N} \mathrm{HCl}$. was also revealed that when diclofenac sodium pellets was coated with the $5 \%$ to $10 \%$ polymer load then burst release of drug was occurred within one hour but this possibility was decreased gradually from $15 \%$ to $30 \%$ polymer load (Figure 3 ). From all formulations it was revealed that the initial drug release was comparable with the terminal drug release which can be attributed due to the presence of

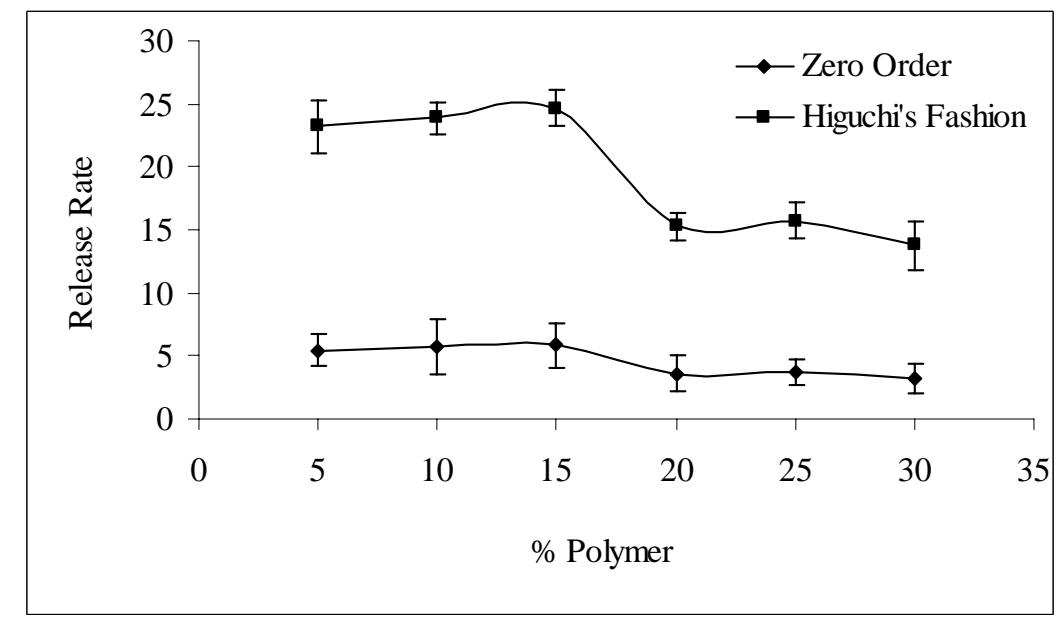

Figure 4. Release rate of diclofenac sodium from coated pellets at different $\%$ of polymer load.

xanthan gum. Xanthan gum displays a high degree of swelling due to water uptake and a small degree of erosion due to polymer relaxation. ${ }^{15-19}$ As Eudragit RS 30 D has initial release retarding nature, contrary xanthan gum is a swellable polymer and due to swell up in the media it facilitates the gel formation at the surface of the pellets which helps the drug to come out easily. Also the short path length for lower

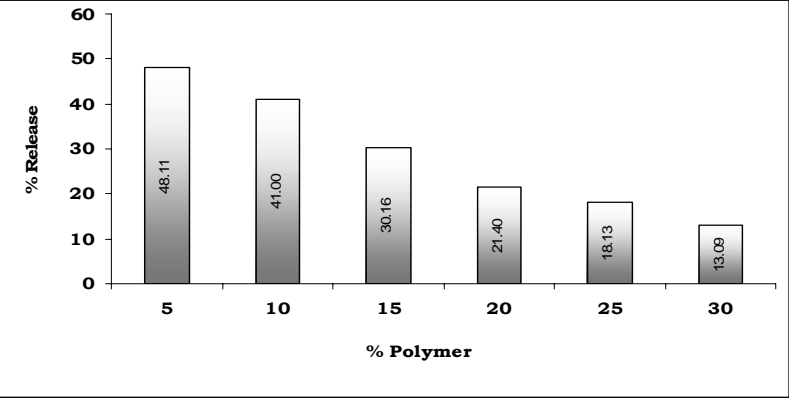

Figure 3. Burst phase release of diclofenac sodium from coated pellets at 1 hour in phosphate buffer 
on the other hand the swelling rate of xanthan gum was decreased which might play the role to retard the release of the drug vigorously and a big difference in drug release was observed between $15 \%$ to $20 \%$ or more polymer load throughout the whole dissolution
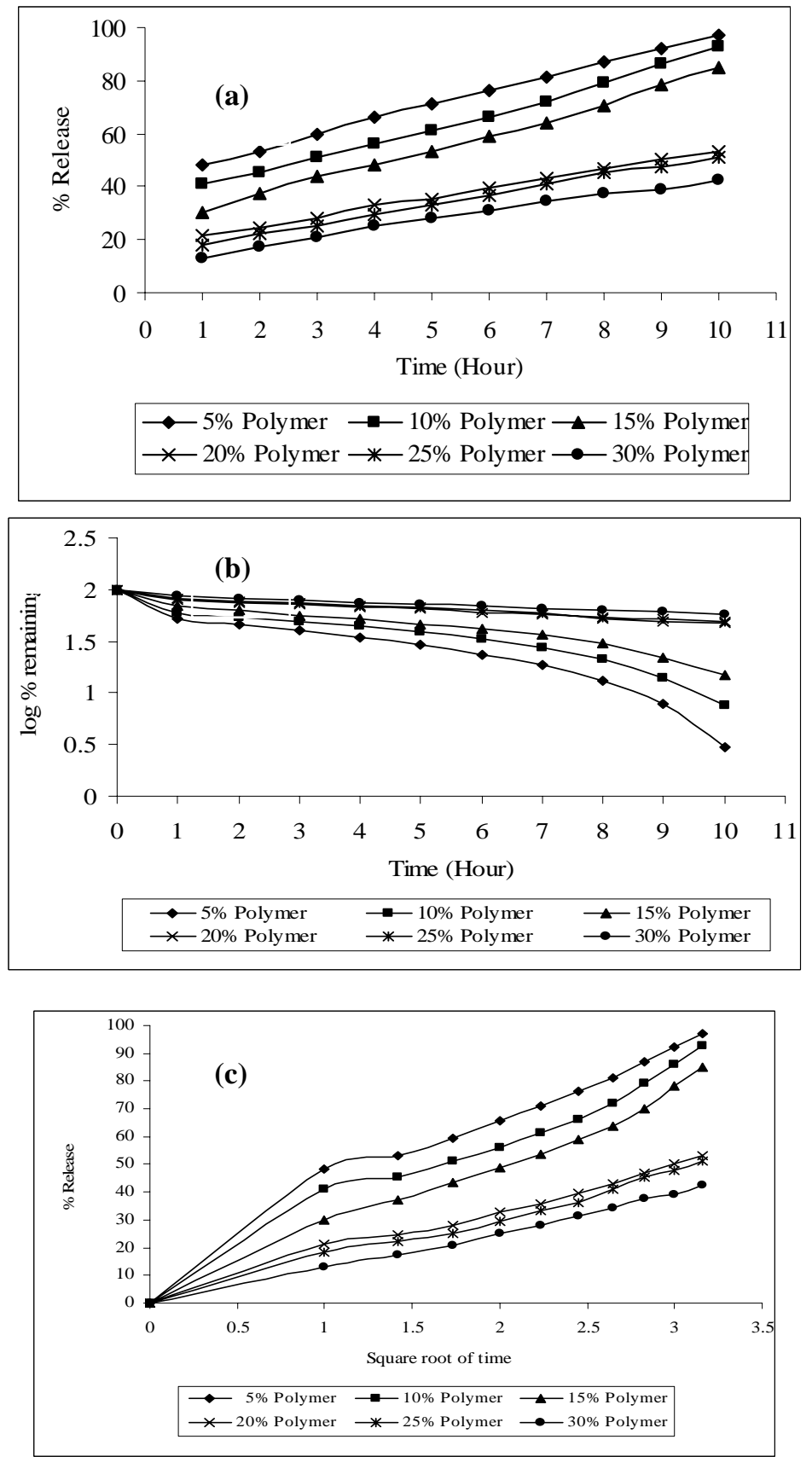

Figure 5. Diclofenac sodium release kinetics from Eudragit RS 30 D \& Xanthan gum (5:1) coated pellets in phosphate buffer. [a-Zero order, b-First order, c-Higuchi plot]

process (Figure 5a). But the low permeability properties of Eudragit RS $30 \mathrm{D}$ as well as the swelling \& erosion behavior of xanthan gum may lead the drug to release linearly throughout the whole dissolution process in aqueous media at $\mathrm{pH}$ $6.8 .^{20-21}$ 
In most of the cases it was revealed that the release kinetics of diclofenac sodium from the coated pellets appeared to follow the mixed release kinetics of zero order $\left(\mathrm{r}^{2}>0.99\right)$, first order $\left(\mathrm{r}^{2}>\right.$ $0.90)$ as well as Higuchi's release kinetics $\left(r^{2}>\right.$ 0.95) (Figure 5a,5b,5c \& Table 2) but zero order release kinetics predominates. The release rate of diclofenac sodium from the coated pellets was seemed to be parallel between the zero order and Higuchi's release kinetics but the highest rate and extend of drug release was observed in Higuchi's release kinetics (Figure 4 ). In case of $20 \%$ or more polymer load the release rate was decreased suddenly, which indicates the more release retarding capability of two polymers during more polymer-drug ratio.

Table 2. Correlation coefficient data $\left(\mathrm{r}^{2}\right)$ at different percent of polymer load.

\begin{tabular}{ccccc}
\hline \multirow{2}{*}{ Polymer combination } & $\begin{array}{c}\text { \% }(\mathrm{w} / \mathrm{w}) \\
\text { polymer }\end{array}$ & \multicolumn{3}{c}{ Correlation coefficient $\left(\mathrm{r}^{2}\right)$} \\
\cline { 3 - 5 } & 5 & 0.9989 & 0.9093 & 0.9847 \\
& 10 & 0.9951 & 0.9137 & 0.9566 \\
Eudragit RS 30 D- & 15 & 0.9949 & 0.9445 & 0.9674 \\
Xanthan Gum (5:1) & 20 & 0.9987 & 0.9613 & 0.9803 \\
& 25 & 0.9982 & 0.9735 & 0.9779 \\
& 30 & 0.9923 & 0.9741 & 0.9939 \\
\hline
\end{tabular}

\section{CONCLUSION}

Although both of the polymers showed better sustaining effect of drug from the coated pellets but from manufacturing point of view xanthan gum may not be a suitable polymer used in the coating formulation due to its swelling properties in aqueous media. Due to its presence the volume of coating solution increases and so as the overall coating time. The surface of the pellets becomes rough during coating and after drying phase. So future research may be initiated which will minimize these problems.

\section{REFERENCES}

1. Shargel, L. and Andrew, B.C. 1941. Modified-release Drug Products and Targeted Drug Delivery System. In: Applied Biopharmaceutics and Pharmacokinetics. $3^{\text {rd }}$ Edn., Appleton \& Lange, USA, pp.225-264.

2. Bidah, D. and Vergnaud, J.M. 1991. Dosage forms with a polymer matrix and a swelling polymer. Int. J. Pharm., 77: 81-87.

3. Bravo, S. AT., Lamas, M.C., Salamon, C.J. 2002. In vitro studies of diclofenac sodium controlled-release from biopolymeric hydrophilic matrices. J. Pharm. Pharm. Sci., 5(3), 213-9.

4. Rao, Y.M., Veni, J.K., Jayasagar, G. 2001. Formulation and evaluation of diclofenac sodium using hydrophilic matrices. Drug Dev. Ind. Pharm., 27(8), 759-66.
5. Sadeghi. F., Ford J.L., Rubinstein, M.H., Rajabi-Siahboomi, A.R. 2000. Comparative study of drug release from pellets coated with HPMC or Surelease. Drug Dev. Ind. Pharm. 26(6), 651-60.

6. Chuanbin, W. and James, W.M. 2001. Influence of Ibuprofen as a Solid-State Plasticizer in Eudragit ${ }^{\circledR}$ RS $30 \mathrm{D}$ on the Physicochemical Properties of Coated Beads AAPS Pharm. Sci. Tech. 2 (4), article 24

7. Okor, R.S. and Obi, C.E. 1990. Drug release through aqueous-based film coatings of acrylate-methacrylate, a water-insoluble copolymer. Int. J. Phamaceutics. 58: 89-91.

8. Lehmann, K. and Dreher, D. 1973. The use of aqueous synthetic polymer dispersions for coating pharmaceutical dosage forms. Drugs made Ger. 16: 126,131,132,134,136.

9. Lehmann, K. and Dreher, D. 1981. Coating of tablets and small particles with acrylic resins by fluid bed technology. Int. J. Pharm. technol. Prod. Manuf. 2(4): 31-43.

10. Kibbe, H.A. 2000. Handbook of Pharmaceutical Excipients. $3^{\text {rd }}$ Edn., American Pharmaceutical Association and Pharmaceutical Press, pp.599-601.

11. Lu, M.F., Woodward, L., Borodkin, S. 1991. Xanthan gum and alginate based controlled release theophylline formulations. Drug Dev. Ind. Pharm. 17, 1987-2004.

12. Dhopeshwarkar, V., Zatz, J.L. 1993. Evaluation of xanthan gum in the preparation of sustained release matrix tablets. Drug Dev. Ind. Pharm. 19, 999-1017.

13. Talukdar, M., Van der Mooter, G., Augustijus, P. 1998. In vivo evaluation of xanthan gum as a potential excipient for oral controlled release matrix tablet formulation. Int. J. Pharmaceutics. 169.105-113. 
14. Sujja-areevath, J., Munday, D.L., Cox, P.J., Khan, K.A., 1998. Relationship between swelling, erosion and drug release in hydrophillic natural gum mini-matrix formulations. Eur. J. Pharm. Sci. 6(3), 207-17.

15. Munday, D.L., Cox, P.J., 2000.Compressed xanthan and karaya gum matrices: hydration, erosion and drug release mechanisms. Int. J. Pharm. 203(1-2), 179-92.

16. Billa, N., Yuen, K.H., Khader, M.A., Omar, A., 2000. Gamma-scintigraphic study of the gastrointestinal transit and in vivo dissolution of a controlled release diclofenac sodium formulation in xanthan gum matrices. Int. J. Pharm. 201(1), 109-20.

17. Billa, N., Yuen, K.H., 2000. Formulation variables affecting drug release from xanthan gum matrices at laboratory scale and pilot scale. AAPS Pharm. Sci. Tech. 1(4), E30.

18. Santos, H., Veiga, F., Pina, M.E., Sousa, J.J., 2004. Compaction, compression and drug release characteristics of xanthan gum pellets of different compositions. Eur. J. Pharm. Sci. 21(2-3), 271-81.
19. Santos, H., Veiga, F., Pina, M.E., Sousa, J.J., 2005.Compaction, compression and drug release properties of diclofenac sodium and ibuprofen pellets comprising xanthan gum as a sustained release agent. Int. J. Pharm. 295(1-2), 15-27.

20. Al-Taani, B.M., Tashtoush, B.M. 2003. Effect of microenvironment $\mathrm{pH}$ of swellable and erodable buffered matrices on the release characteristics of diclofenac sodium. AAPS Pharm. Sci. Tech. 4(3), E43.

21. Sujja-areevath, J., Munday, D.L., Cox, P.J., Khan, K.A. 1998. Relationship between swelling, erosion and drug release in hydrophillic natural gum mini-matrix formulations. Eur. J. Pharm. Sci. 6(3), 207-17. 